\title{
Dopant Distribution in Atomic Layer Deposited ZnO:Al Films Visualized by Transmission Electron Microscopy and Atom Probe Tomography
}

\author{
Yizhi Wu, ${ }^{\dagger}$ A. Devin Giddings, ${ }^{\ddagger}$ Marcel A. Verheijen, ${ }^{\dagger}$ Bart Macco, ${ }^{\dagger} \odot$ Ty J. Prosa, ${ }^{\ddagger}$ David J. Larson, ${ }^{\ddagger}$
} Fred Roozeboom, ${ }^{\dagger, \S}$ and Wilhelmus M. M. Kessels*,†ं

${ }^{\dagger}$ Eindhoven University of Technology, P.O. Box 513, 5600 MB Eindhoven, The Netherlands

${ }^{\ddagger}$ CAMECA Instruments Inc., 5500 Nobel Drive, Madison, Wisconsin 53711, United States

${ }^{\S}$ Holst Centre, P.O. Box 8550, 5605 KN Eindhoven, The Netherlands

Supporting Information

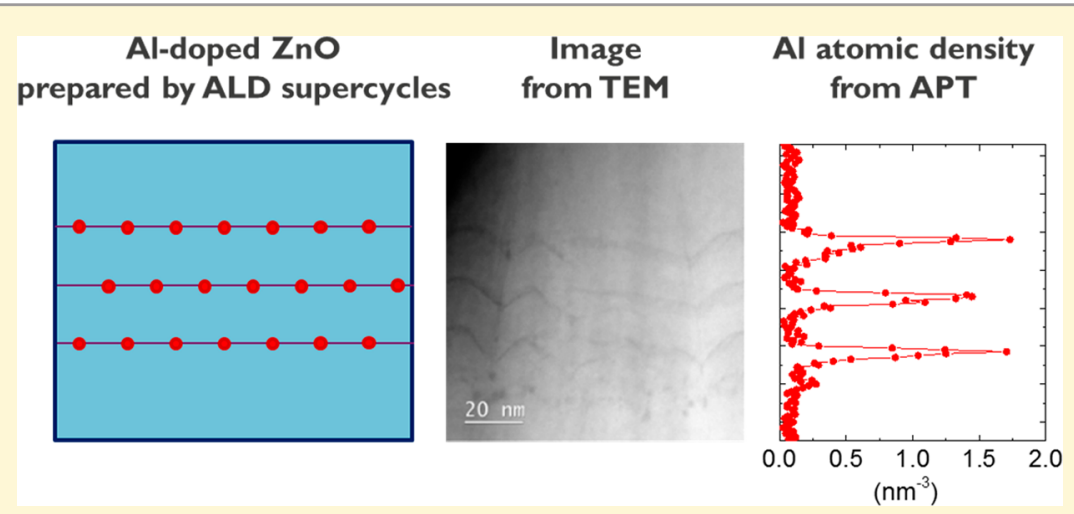

ABSTRACT: The maximum conductivity achievable in Al-doped $\mathrm{ZnO}$ thin films prepared by atomic layer deposition (ALD) is limited by the low doping efficiency of Al. To better understand the limiting factors for the doping efficiency, the threedimensional distribution of $\mathrm{Al}$ atoms in the $\mathrm{ZnO}$ host material matrix has been examined on the atomic scale using a combination of high-resolution transmission electron microscopy (TEM) and atom probe tomography (APT). Although the Al distribution in $\mathrm{ZnO}$ films prepared by so-called "ALD supercycles" is often presented as atomically flat $\delta$-doped layers, in reality a broadening of the Al-dopant layers is observed with a full-width-half-maximum of $\sim 2 \mathrm{~nm}$. In addition, an enrichment of the Al at grain boundaries is observed. The low doping efficiency for local Al densities $>\sim 1 \mathrm{~nm}^{-3}$ can be ascribed to the Al solubility limit in $\mathrm{ZnO}$ and to the suppression of the ionization of $\mathrm{Al}$ dopants from adjacent $\mathrm{Al}$ donors.

\section{INTRODUCTION}

Transparent conducting oxide (TCO) thin films are a class of materials that are commonly used as transparent electrodes in a wide variety of commercial optoelectronic devices, most prominently displays and solar cells. ${ }^{1-3}$ The most commonly used TCO is indium tin oxide (ITO). Although this material yields very good optoelectronic properties, widespread use, particularly for large-scale applications, is hampered by the scarcity of indium. Another TCO is $\mathrm{ZnO}$, for which there is an abundant availability of constituent materials, and therefore $\mathrm{ZnO}$ has been reported to be a promising, low cost alternative to ITO. ${ }^{4}$ However, one key requirement for TCOs in many applications is a film resistivity on the order of $1 \mathrm{~m} \Omega \cdot \mathrm{cm}$ or lower. ${ }^{5}$ For $\mathrm{ZnO}$, this can be achieved through cation doping, with $\mathrm{Al}$ being the most commonly used dopant. This material is known as Aldoped $\mathrm{ZnO}$, abbreviated as $\mathrm{ZnO}: \mathrm{Al}$ or $\mathrm{AZO}$.

There are several methods by which $\mathrm{ZnO}: \mathrm{Al}$ thin films can be prepared, each with their pros and cons. Furthermore, each of these methods results in particular properties of the resultant films. Physical vapor deposition (PVD), in particular sputtering, and chemical vapor deposition (CVD) methods have been most popular, and with these methods resistivity values on the order of $0.1 \mathrm{~m} \Omega \cdot \mathrm{cm}$ have been achieved for $\mathrm{ZnO}: \mathrm{Al}$ thin films. ${ }^{5}$ However, compared to these methods, atomic layer deposition (ALD) ${ }^{6-10}$ can provide a number of advantages that are particularly relevant for demanding emerging applications: $(i)$ The cyclic nature of ALD allows accurate control of film thickness even for ultrathin films. (ii) ALD offers excellent uniformity, necessary for large area applications. (iii) ALD is unique in its ability to cover challenging surface topologies with a very high degree of conformality. (iv) The absence of energetic species (ions, neutrals, photons) makes it a "mild" deposition technique, which does not cause damage to the underlying surface. ${ }^{10,11}(v)$ ALD processes work at relatively low temperatures, making the

Received: August 30, 2017

Revised: February 2, 2018

Published: February 5, 2018 
technique suitable for situations where thermal budgets are restricted, and finally, $(v i)$ the atomic composition and hence the doping level can, in principle, be accurately controlled in a highly repeatable manner by tuning the ALD cycle ratio between the host matrix and dopant materials.

Despite the advantages of growing $\mathrm{ZnO}$ :Al thin films by ALD, the improvement in resistivity by $\mathrm{Al}$ doping is still limited. For example, in previous work using the commonly applied trimethyl aluminum precursor (TMA, $\left.\left[\mathrm{Al}\left(\mathrm{CH}_{3}\right)_{3}\right]_{2}\right),{ }^{12}$ it was shown that by varying the $\mathrm{Al}$ doping level (defined as the proportion of $\mathrm{Zn}$ atoms replaced by $\mathrm{Al}$; see below), the resistivity could be improved from $9.8 \mathrm{~m} \Omega \cdot \mathrm{cm}$ to $2.2 \mathrm{~m} \Omega \cdot \mathrm{cm}$. However, this is still not sufficient to meet the required performance target of $<1 \mathrm{~m} \Omega$. $\mathrm{cm}$. Furthermore, the doping efficiency, i.e., the percentage of $\mathrm{Al}$ atoms that act as active dopants, releasing free electrons, is generally lower than $10 \%$. The inactive $\mathrm{Al}$ atoms can act as scattering centers rather than contributing to the number of free electrons. This will have a negative effect on the carrier mobility and hence on the electrical transport in the $\mathrm{ZnO}: \mathrm{Al}$ films.

The limited improvement in conductivity and the low doping efficiency of ALD-ZnO:Al have been attributed as principally being due to the inhomogeneous distribution of the $\mathrm{Al}$ atoms in $\mathrm{ZnO}$ :Al films, originating from the so-called "supercycle" growth mode. ${ }^{8,12,13}$ As shown in Figure 1a, one supercycle consists of $m$ $\mathrm{ZnO}$ cycles and one $\mathrm{Al}_{2} \mathrm{O}_{3}$ cycle, where $m$ is called the cycle ratio. By modifying this cycle ratio, the doping level can be tuned. The targeted film thickness can be achieved by repeating a certain number $N$ of these supercycles. Such a growth mode can lead to a lamellar distribution of $\mathrm{Al}$ atoms in the $\mathrm{ZnO}: \mathrm{Al}$ films, as shown schematically (and idealized) in Figure $1 \mathrm{~b}$. To increase the $\mathrm{Al}$ doping level, the cycle ratio $m$ is lowered, which will correspondingly decrease the spacing, $l$, between the adjacent Al-dopant layers. Our previous work revealed two distinct regimes for $\mathrm{ZnO}$ :Al films prepared as a function of cycle ratio $m$. It was shown that the doping efficiency is approximately constant when the spacing $l$ of adjacent $\mathrm{Al}$-dopant layers is higher than a critical value of $l_{\mathrm{c}}=3.8 \mathrm{~nm}$, which corresponds to a doping level of $6.9 \%{ }^{12}$ In this region, the resistivity decreases with increasing cycle ratio $m$. For $l<l_{\mathcal{c}}$, the doping efficiency drops and the resistivity increases with $m$. Such a correlation between the doping efficiency and the spacing $l$ has also been observed by Lee et al., ${ }^{8}$ who reported that $l_{\mathrm{c}}$ ranged from 2.3 to $2.6 \mathrm{~nm}$ for their films.

When correlating the doping efficiency with the spacing between the Al-dopant layers, it should be realized that the spacing only describes the dopant distribution in the growth direction. The areal density of $\mathrm{Al}$ atoms within each individual $\mathrm{Al}$ dopant layer can also play a role. There have been two experimental studies that support this, showing that by increasing the lateral distance of $\mathrm{Al}$ atoms in the $\mathrm{Al}$-dopant layers, the doping efficiency can be increased and the film resistivity can be lowered. ${ }^{13,14}$ In one of these studies, the number of $\mathrm{Al}$ atoms incorporated in one ALD cycle was reduced by deactivating a fraction of the surface functional groups on which TMA molecules can chemisorb. The deactivation took place by using ethanol as a reactant before the dosing step of TMA. This approach improved the doping efficiency by a factor of $\sim 2 .{ }^{13}$ In another approach dimethylaluminum isopropoxide (DMAI, $\left.\left[\mathrm{Al}\left(\mathrm{CH}_{3}\right)_{2}\left(\mu-\mathrm{O}^{i} \mathrm{Pr}\right)\right]_{2}\right)$ was selected as an alternative $\mathrm{Al}$ precursor to TMA. ${ }^{14}$ Due to steric hindrance of the larger $\mathrm{O}^{i} \mathrm{Pr}$ ligand, the number of $\mathrm{Al}$ atoms deposited per $\mathrm{Al}_{2} \mathrm{O}_{3}$ cycle was significantly reduced from 11.0 to $2.9 \mathrm{~nm}^{-2}$. As a result, a higher doping efficiency of $50-60 \%$ compared to $<10 \%$ for TMA and a lower
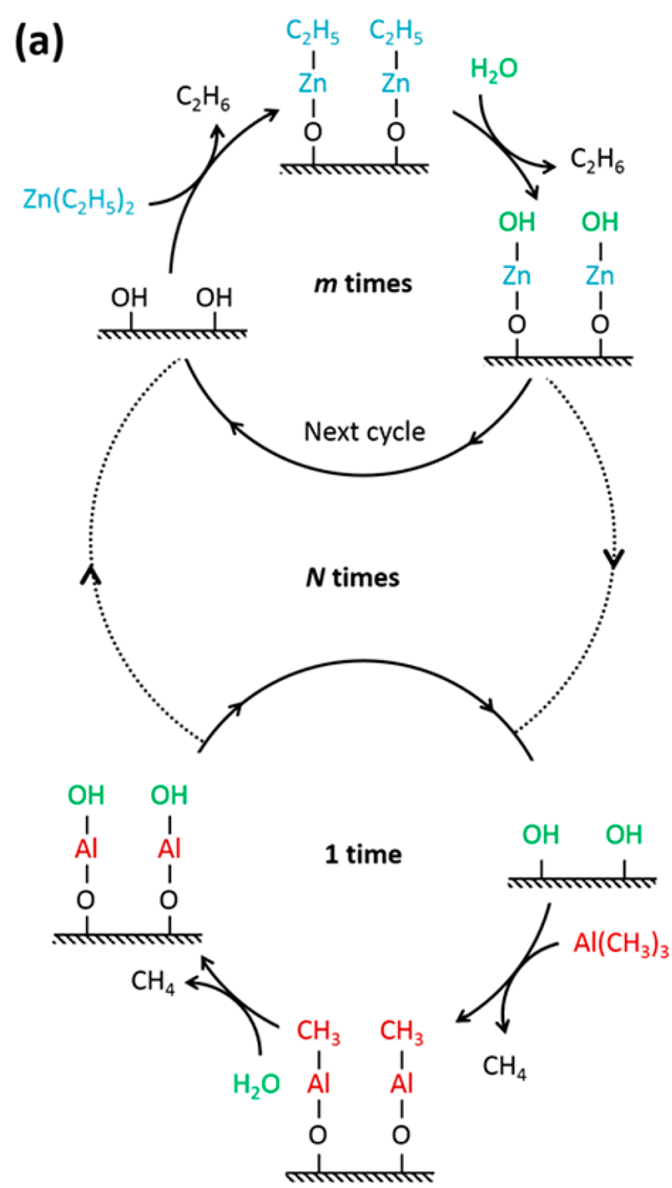

(b)

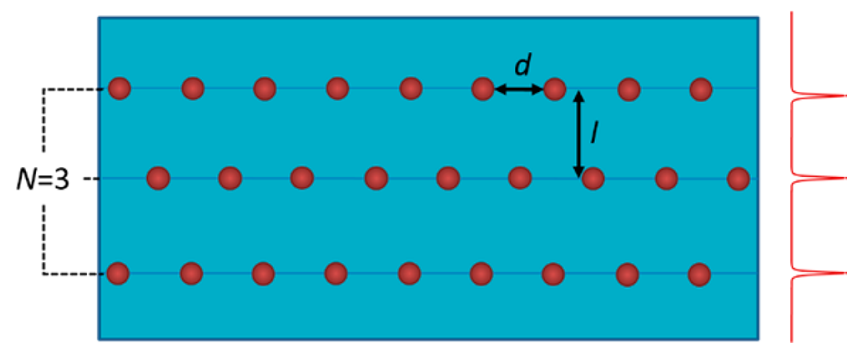

Figure 1. (a) Schematic representation of one ALD supercycle for the preparation of $\mathrm{ZnO}: \mathrm{Al}$ films. One supercycle, carried out $\mathrm{N}$ times, consists of $m$ cycles of $\mathrm{ZnO}$ and one cycle of $\mathrm{Al}_{2} \mathrm{O}_{3}$, where $m$ is called the cycle ratio. One individual $\mathrm{ZnO}$ or $\mathrm{Al}_{2} \mathrm{O}_{3} \mathrm{ALD}$ cycle consists of four steps: precursor dosing/purge/coreactant dosing/purge. Diethylzinc (DEZ), trimethylaluminum (TMA), and deionized water vapor serve as the $\mathrm{Zn}$ precursor, $\mathrm{Al}$ precursor, and coreactant, respectively. (b) Schematic and idealized representation of a $\mathrm{ZnO}$ :Al film prepared by repeating $N$ ALD supercycles as shown in a. The $\mathrm{Al}$ dopant atoms are indicated assuming an idealized $\delta$-function distribution. The vertical spacing $l$ between adjacent dopant layers is determined by the cycle ratio $m$. The lateral spacing between dopants is $d$.

resistivity of $0.7 \mathrm{~m} \Omega \cdot \mathrm{cm}$ compared to $2.4 \mathrm{~m} \Omega \cdot \mathrm{cm}$ for TMA was achieved. ${ }^{11,14} \mathrm{~A}$ similar effect was achieved for $\mathrm{ZnO}$ : $\mathrm{B}$ using the relatively large precursor triisopropyl borate $\left(\mathrm{TIB},\left[\mathrm{B}\left(\mathrm{O}^{i} \mathrm{Pr}\right)\right]_{3}\right)$ for B doping. ${ }^{15}$

Obviously, the doping level and the doping efficiency of Aldoped $\mathrm{ZnO}$ films prepared by ALD are important factors determining the performance of the films for TCO applications, 
Table 1. Properties of the ZnO:Al Films with Thicknesses of $40 \pm 2 \mathrm{~nm}$ As Studied by APT and TEM ${ }^{a}$

\begin{tabular}{|c|c|c|c|c|c|c|c|c|}
\hline \multirow[b]{2}{*}{ layer } & \multicolumn{3}{|c|}{ growth parameters } & \multirow{2}{*}{$\begin{array}{c}\text { doping level } \\
\mathrm{Al}_{\text {fraction }} \\
\mathrm{AF}_{\text {global }}(\%)\end{array}$} & \multicolumn{4}{|c|}{ electrical properties } \\
\hline & supercycles $N$ & cycle ratio $m$ & $\underset{(\mathrm{nm})}{\operatorname{spacing} l}$ & & resistivity $\rho(\mathrm{m} \Omega \cdot \mathrm{cm})$ & $\begin{array}{l}\text { carrier density } n_{\mathrm{e}} \\
\quad\left(10^{20} \mathrm{~cm}^{-3}\right)\end{array}$ & $\begin{array}{c}\text { mobility } \mu \\
\left(\mathrm{cm}^{2} \mathrm{~V}^{-1} \mathrm{~s}^{-1}\right)\end{array}$ & $\begin{array}{c}\text { doping efficiency } \\
\eta(\%)\end{array}$ \\
\hline AZO-1 & 3 & 85 & 13.7 & 1.9 & 5.1 & 1.1 & 10.8 & 7.1 \\
\hline AZO-2 & 11 & 23 & 3.8 & 6.9 & 2.4 & 3.0 & 8.7 & 8.7 \\
\hline AZO-3 & 19 & 12 & 2.0 & 16.4 & 4.9 & 3.7 & 3.5 & 4.7 \\
\hline
\end{tabular}

${ }^{a}$ The films have been selected as typical representatives of $\mathrm{ZnO}$ :Al films with lowly-doped (AZO-1), optimally-doped (AZO-2), and highly-doped (AZO-3) Al doping levels. ${ }^{12}$ The spacing $l$ indicates the vertical distance between adjacent AlOx layers. The doping level in the $\mathrm{ZnO}: \mathrm{Al}$ films is characterized by the $\mathrm{Al}$ fraction in the films as measured by XPS. ${ }^{12}$ The electrical properties were measured for films deposited on p-Si wafers with $450 \mathrm{~nm}$ thermal oxide. ${ }^{12}$

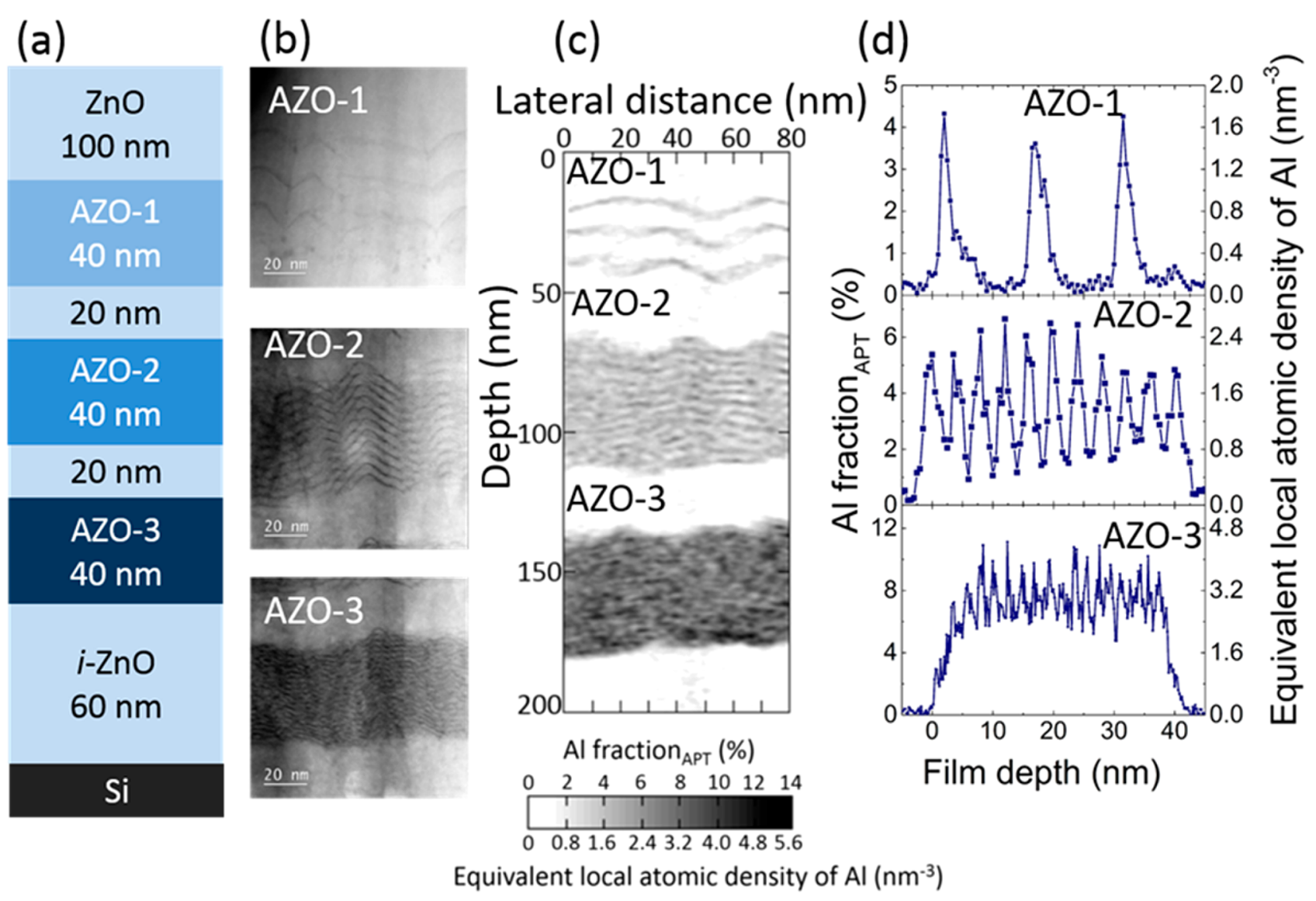

Figure 2. (a) Schematic representation of the structure of the $\mathrm{ZnO} / \mathrm{ZnO}$ :Al film stack prepared on a Si substrate and on a microtip coupon for TEM and APT analysis, respectively. (b) High-resolution HAADF-STEM images of the three $\mathrm{ZnO}: \mathrm{Al}$ films. (c) Two-dimensional depth profile of the Al fraction measured by APT showing the Al distribution in the film stack for a projected volume with a depth of $5 \mathrm{~nm}$. (d) One-dimensional local depth profile of the $\mathrm{Al}$ fraction in the three $\mathrm{ZnO}$ : Al films measured by APT. These profiles are extracted from a cylindrical subvolume with a diameter of $15-20 \mathrm{~nm}$ from a region carefully selected (avoiding grain boundaries) in which the interface between the $\mathrm{ZnO}$ matrix and the $\mathrm{Al}$-dopant layers are approximately locally flat and oriented normally to the sampling direction.

and they depend largely on how the Al-dopant atoms in the films are distributed. The conventional view that the $\mathrm{Al}$ atoms are concentrated only at distinct film depths in a perfect arrangement (as illustrated in Figure $1 \mathrm{~b}$ ) - a so-called $\delta$-doping profile-is clearly an oversimplification. The Al-dopant layers might be broadened by intermixing effects and by the influence of surface roughness, while also the occurrence of grain boundaries in the polycrystalline matrix can play a role. Therefore, in this work, we investigate the distribution of $\mathrm{Al}$ atoms in $\mathrm{ZnO}: \mathrm{Al}$ and discuss how this distribution affects the doping efficiency. To do so, we prepared $\mathrm{ZnO}: \mathrm{Al}$ thin films by ALD using the conventional $\mathrm{Al}$ precursor TMA in the supercycle growth mode. The spatial distribution of the $\mathrm{Al}$ atoms was obtained at an atomic resolution by transmission electron microscopy (TEM) and atom probe tomography (APT). The latter is a tool for 3D imaging of the composition of thin films at the atomic scale, which is found to be particularly powerful for doped films. ${ }^{16-19}$

\section{EXPERIMENTAL SECTION}

Intrinsic and $\mathrm{Al}$-doped $\mathrm{ZnO}$ films were prepared using an Oxford Instruments OpAL ALD reactor at a substrate temperature of $250^{\circ} \mathrm{C}$. Diethylzinc (DEZ, $\left.\mathrm{Zn}\left(\mathrm{C}_{2} \mathrm{H}_{5}\right)_{2}\right)$, TMA, and deionized water vapor were used as precursors. ${ }^{12}$ From our previous work, ${ }^{12}$ we have identified the supercycle conditions to grow the three types of $\mathrm{ZnO}: \mathrm{Al}$ films that can be representatively labeled as lowly, optimally, and highly doped films. Table 1 describes the growth parameters used to create the three conditions as well as the resulting electrical properties. The number of 
supercycles, $N$, is the number of $\mathrm{Al}_{2} \mathrm{O}_{3}$ ALD cycles used in each film's deposition. These values are 3 (lowly doped), 11 (optimally doped), and 19 (highly doped), respectively, for the films denoted AZO-1 to AZO-3. Earlier, we reported that a minimum resistivity of $2.4 \mathrm{~m} \Omega \cdot \mathrm{cm}$ was obtained for the optimally doped case AZO-2. For comparison, the low doping in AZO-1 results in a lower carrier density, while the high doping in film AZO-3 leads to a lower carrier mobility.

In Table 1 , the doping level is presented by the aluminum fraction $(\mathrm{AF})$, which represents the fraction of $\mathrm{Zn}$ atoms replaced by $\mathrm{Al}$ atoms in the $\mathrm{ZnO}: \mathrm{Al}$ film. The value of $\mathrm{AF}$ is given by

$$
\mathrm{AF}=\frac{[\mathrm{Al}]}{[\mathrm{Al}]+[\mathrm{Zn}]}
$$

The atomic percentages of $\mathrm{Zn}$ and $\mathrm{Al}$ were measured either by $\mathrm{X}$-ray photoelectron spectroscopy (XPS), denoted as $\mathrm{AF}_{\text {global }}$, or by APT, denoted as $\mathrm{AF}_{\text {local }}$. Note that $\mathrm{AF}_{\text {global }}$ represents the averaged $\mathrm{Al}$ doping level throughout an entire $\mathrm{ZnO}: \mathrm{Al}$ film, while $\mathrm{AF}_{\text {local }}$ represents an $\mathrm{Al}$ doping level of a selected nanoscale subvolume of the AZO film, extracted from the APT data set.

In this work, a stack was prepared consisting of three $\mathrm{ZnO}: \mathrm{Al}$ films with a film thickness of $40 \pm 2 \mathrm{~nm}$ each. The conditions for the $\mathrm{ZnO}: \mathrm{Al}$ films were identical to those used as the films listed in Table 1 . In the stack, the $\mathrm{ZnO}: \mathrm{Al}$ films were separated and capped by intrinsic $\mathrm{ZnO}$ films as shown schematically in Figure 2a. This geometry enabled data collection on all three film types in a single APT and TEM measurement. Within one deposition run, the stack was prepared on both a Si substrate for the TEM measurements and on a commercially available Si microtip array coupon with flat-top Si microtips for the APT measurements. A native oxide was present on both the Si substrate and the Si microtip array coupon.

As mentioned, the complete stack also contained a $\mathrm{ZnO}$ capping film and $\mathrm{ZnO}$ buffer films between the three $\mathrm{ZnO}: \mathrm{Al}$ films of interest. The top $100 \mathrm{~nm} \mathrm{ZnO}$ cap film served two purposes: (i) during focused ion beam (FIB) milling, it was used as a sacrificial film to protect the $\mathrm{ZnO}: \mathrm{Al}$ films from ion implantation, which could damage the structure, and (ii) it provided sufficient material for the apex of the APT specimen needles to reach an equilibrium shape during the initial stages of field evaporation, before the film of interest was reached. The two $20-\mathrm{nm}$ thick $\mathrm{ZnO}$ buffer films grown between the $\mathrm{ZnO}$ : $\mathrm{Al}$ films were intended (i) to clearly separate $\mathrm{ZnO}: \mathrm{Al}$ films for the TEM and APT imaging and data collection and (ii) to allow the APT specimen apex to return to an equilibrium shape between each $\mathrm{ZnO}: \mathrm{Al}$ film. This prevented changes of the specimen's equilibrium tip shape, expected to occur during field evaporation of one film, from influencing the measured geometry of the next. The $60 \mathrm{~nm} i$ - $\mathrm{ZnO}$ film at the bottom was deposited to provide sufficient material so that the third $\mathrm{ZnO}: \mathrm{Al}$ film could be completely evaporated before the field evaporation of the APT specimen reaches the Si substrate layer.

The flat-top Si microtips upon which the deposition was made had an initial diameter of $\sim 2 \mu \mathrm{m} .{ }^{20}$ After the ALD coating, they were prepared using standard FIB annular milling protocols ${ }^{21,22}$ into APT specimen needles with an initial diameter of $\sim 50 \mathrm{~nm}$ and half shank angle of $\sim 15^{\circ}$. By depositing directly onto the microtip coupon, the APT specimens could be prepared with reduced FIB requirements since no lamella liftout was necessary. High resolution SEM images of the specimen needles were taken before APT measurement and, when possible, after the measurement to provide geometric information to assist with the data reconstruction. Deposition onto presharpened microtips ${ }^{20}$ with an initial diameter $\sim 10 \mathrm{~nm}$ was also prototyped, but this proved inferior to using the flat-top type. The APT measurements were performed in CAMECA LEAP 4000X microscopes ${ }^{23}$ with the specimen at a temperature of $25 \mathrm{~K}$, laser pulse energies between $0.3 \mathrm{pJ}$ and $10 \mathrm{pJ}$, and laser pulse repetition rates of $160 \mathrm{kHz}$ (reflectron-type system) or $500 \mathrm{kHz}$ (straight-flight path system). Cross-sectional TEM studies on FIB prepared lift-out samples were performed in high-angle annular dark-field (HAADF) STEM and in bright-field TEM modes using a probe-corrected TEM (JEOL JEM ARM 200F) equipped with a 100 $\mathrm{mm}^{2}$ Centurio SDD detector and a FEI Tecnai F30ST TEM. Note that all results presented were obtained from one APT specimen and one TEM specimen (both deposited in the same run).

\section{RESULTS}

Two-Dimensional Depth Profiles. The morphology of the three $\mathrm{ZnO}$ :Al films has been imaged by both TEM and APT. The lamellar structures of the $\mathrm{ZnO}$ :Al films were imaged in HAADFSTEM mode as shown in Figure $2 \mathrm{~b}$. The dark streaks represent the positions of the Al-dopant layers, where $\mathrm{Al}$ atoms were incorporated during single $\mathrm{Al}_{2} \mathrm{O}_{3} \mathrm{ALD}$ cycles of the supercycle. Figure $2 \mathrm{c}$ shows the two-dimensional (2D) profiles of the $\mathrm{Al}$ distribution in the stack, extracted from the $3 \mathrm{D}$ APT data. The projected volume for the $2 \mathrm{D}$ APT profiles has a depth of $5 \mathrm{~nm}$. The gray scale shading in the $2 \mathrm{D}$ APT profiles represents the $\mathrm{Al}$ doping levels and is quantified by $\mathrm{AF}_{\text {local }}$. Consistent with the TEM images, the gray streaks in Figure $2 \mathrm{c}$ indicate the $\mathrm{Al}$-dopant layers. In both cases, rather than being flat, the Al-dopant layers are observed to be ridged. This reflects the faceting of the $\mathrm{ZnO}: \mathrm{Al}$ polycrystalline $^{12}$ grains (grain size is $\sim 40 \mathrm{~nm}$, see below) obtained for the ALD-prepared films.

The equivalent estimated local atomic density of $\mathrm{Al}$ is also indicated in Figure 2c. This parameter is derived from $\mathrm{AF}_{\text {local }}$ by multiplying $\mathrm{AF}_{\text {local }}$ with the bulk atomic density of $\mathrm{Zn}$ in the undoped $\mathrm{ZnO}$ films, which is estimated at $4.0 \times 10^{22} \mathrm{~cm}^{-3}$ from our previous work. ${ }^{12}$ In both the TEM images and the $2 \mathrm{D}$ APT profile, 3 and 11 individual Al-dopant layers can be distinguished in the AZO-1 and AZO-2 films, respectively. These values are consistent with the number of supercycles, $N$, used to incorporate $\mathrm{Al}$ into these two films, as shown in Table 1 . The AZO-3 film with $N=19$ has a lamellar structure that is less clearly resolved in both the TEM (Figure 2b) and the APT profiles (Figure 2c). This can be attributed to the smaller cycle ratio, $m$, leading to a relatively small spacing between the Al-dopant layers $(l=\sim 2 \mathrm{~nm})$ as well as to the projection of fine-scale surface roughness on the $2 \mathrm{D}$ profiles and the broadening of the $\mathrm{Al}$ dopant layers. The latter will be addressed in the next section.

One-Dimensional Local Depth Profiles. One-dimensional (1D) local depth profiles created from the 3D APT data are presented in Figure 2d. The term "local" is used to emphasize that the profiles are not the projections from the entire $3 \mathrm{D}$ data sets shown in Figure $2 \mathrm{~b}$ but instead are collected from cylindrical subvolumes with a diameter of 15 or $20 \mathrm{~nm}$. The subvolumes are carefully selected from regions within a grain in which the interfaces between the $\mathrm{ZnO}$ matrix and the $\mathrm{Al}$-dopant layers were close to being flat for an area with the size of the cylindrical crosssection, for all the dopant layers in the subvolume. The cylindrical subvolumes were oriented to be normal to the interface plane, which, because of the faceting, would not necessarily be parallel to the local growth direction of the film. However, given the scale of the roughness, particularly in the case of layer AZO-2, it must be accepted that it is not possible to have a perfectly positioned analysis subvolume, a factor that will introduce apparent interface broadening into the $1 \mathrm{D}$ profiles. Despite this, individual peaks, which represent the Al-dopant layers, are observed in all three $\mathrm{ZnO}: \mathrm{Al}$ films. Both the number of peaks and the spacing between the peaks are consistent with the conditions and film properties, as listed in Table 1, in particular the number of supercycles, $N$.

These $1 \mathrm{D}$ profiles clearly show that the distribution of $\mathrm{Al}$ in the depth direction is not a $\delta$ function. Instead, from the full shape of the peaks in the upper profile in Figure 2d, it can be estimated that the peaks have a full-width-half-maximum (fwhm) of $\sim 2$ $\mathrm{nm}$. The $\mathrm{Al}$ atoms in a single $\mathrm{Al}$-dopant layer are incorporated 

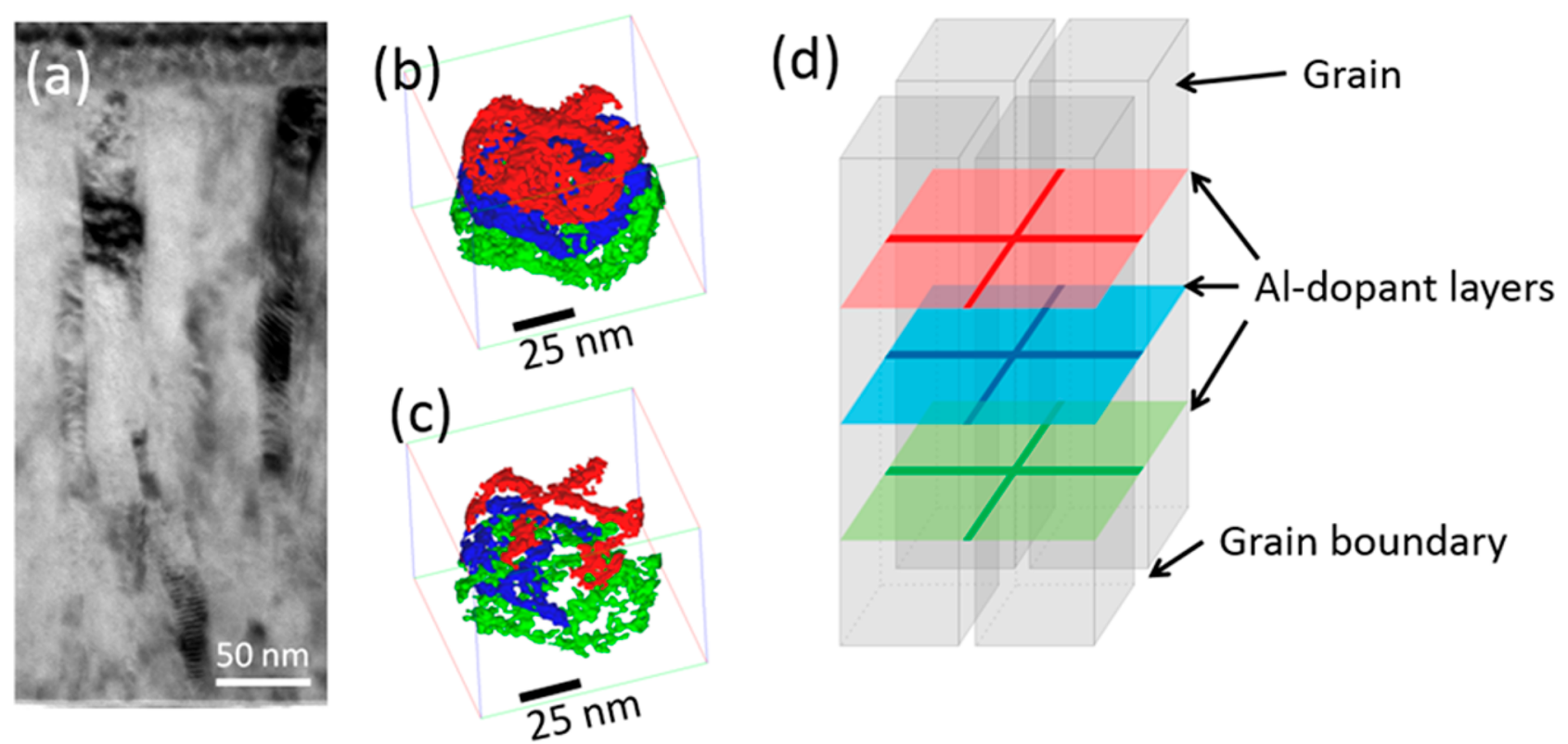

Figure 3. (a) Cross-sectional bright-field TEM image of the entire film stack as schematically shown in Figure 1a. Iso-concentration surfaces created from the APT data set at $(\mathrm{b}) \mathrm{AF}_{\text {local }}=1.7 \%$ and $(\mathrm{c}) \mathrm{AF}_{\text {local }}=3.0 \%$ in the AZO-1 film. This layer was prepared with three supercycles, as can also be observed from the three Al-dopant layers in the plots (each have been assigned a different color for clarity). (d) Schematic representation illustrating different $\mathrm{AF}_{\text {local }}$ regions within the grains and at grain boundaries in the AZO-1 film. The gray rectangular boxes represented the columnar-shaped $\mathrm{ZnO}: \mathrm{Al}$ grains as observed in a. The gaps in between represent the grain boundaries and the colored planes, the Al-dopant layers. These correspond to the iso-concentration surfaces in $\mathrm{b}$. The grid-shaped patterns within the planes represent a high density of $\mathrm{Al}$ atoms at the grain boundaries, and they correspond to the iso-concentration surfaces in c. $\mathrm{AF}_{\text {local }}$ is above $3 \%$ in the cross-shape patterns and between $1.7 \%$ and $3 \%$ in the colored planes. Twodimensional concentration maps of the three layers shown in $b$ and $c$ are given in the Supporting Information (Figure S2).

into the film by a single ALD cycle that has a growth rate of 0.1 $\mathrm{nm} /$ cycle. Compared to this width of $0.1 \mathrm{~nm}$, the fwhm of $2 \mathrm{~nm}$ represents a significant broadening of the Al-dopant layers. Note that in the upper profile of Figure $2 \mathrm{~d}$, an asymmetric peak broadening is observed: more downward broadening than upward. Asymmetric interface profiles in APT data must be treated with caution because local magnification effects can occur when the layers have different evaporation fields, leading to fluctuations in the atomic density and thus reduced fidelity of spatial position. ${ }^{24,25}$ However, in the case of the current measurements, the density fluctuations in the $1 \mathrm{D}$ profile are such that there is an apparent higher atomic density on the interface going from the $\mathrm{AlO}_{x}$ layer (higher evaporation field) to $\mathrm{ZnO}$ (lower evaporation field). This would, therefore, tend to suppress the perceived downward broadening rather than enhance it.

There are three potential reasons for the measured broadening in the 1D profiles: ( $i$ ) the roughness of the layer and a misalignment from the normal of the sampling volume to each of the surfaces, causing projection effects; (ii) the resolution limit of the technique; and (iii) an actual vertical spread of the $\mathrm{Al}$ atoms in the films.

Option $i$ reflects the issues in extracting local compositional information from a sample with a complex $3 \mathrm{D}$ geometry. In the samples studied here, the surface topography of all layers within the stacks varies strongly along each interface. For instance, the volume of the AZO-2 stack depicted in Figure $2 \mathrm{~b}$ would not allow for extracting a 20-nm-wide cylindrical volume perpendicular to the interfaces without having significant interface broadening. As mentioned, by taking this into account, the location and size of the 15-20 nm diameter sampling cylinder was chosen based on the shape of the layers to provide a suitable compromise between sharper profiles and sufficient composi- tional sensitivity. By such careful selection of the subvolumes in the APT data sets, the effect of projected interface broadening was minimized and is expected to be significantly less than $2 \mathrm{~nm}$.

Option $i i$ assumes that the limit of the spatial resolution of $\mathrm{APT}$ has resulted in broadening of the $\mathrm{Al}$ profiles. This resolution is highly specimen dependent. In some publications the depth resolution of APT is reported to be better than $0.4 \mathrm{~nm} /$ decade, $^{26-28}$ and for some materials, the reconstruction of individual atomic planes is used to demonstrate "atomic" resolution. ${ }^{27}$ However, for measurement of compound semiconductors, the field evaporation behavior is often too disordered to achieve such precision. As mentioned before, the broadening of the peaks of the $\mathrm{Al}$-dopant layers in the AZO-1 film is estimated to have an fwhm of $2 \mathrm{~nm}$. By simulating the $\mathrm{Al}$ profiles as $\delta$-functions and assuming all the peak broadening is a result of the experimental profile, described by a Gaussian broadening function, we can estimate an upper-bound to this factor (see Supporting Information, Figure S1). From the degree of separation observed in the $1 \mathrm{D}$ profile of the AZO-3 film, we can conclude that the contribution of the potential instrument resolution limitation to the peak broadening is narrower than $\sim 1.5 \mathrm{~nm}$ fwhm. This suggests that there must be additional broadening of the peaks other than potential instrument resolution limitations.

Having dismissed measurement and instrumental artifacts to be the sole cause of the broadened $\mathrm{Al}$ distribution, option iii must be considered, i.e., a physical reason for a vertical distribution of $\mathrm{Al}$ dopants. Thermally driven atomic diffusion of $\mathrm{Al}$ into a $\mathrm{ZnO}$ matrix has been observed in other experiments but appears to be relevant only when the samples are annealed at temperatures higher than $800{ }^{\circ} \mathrm{C}$ because of the high activation energy for diffusion of $\mathrm{Al}$ in $\mathrm{ZnO}\left(E_{\mathrm{a}}=\sim 2.8 \mathrm{eV}\right) .{ }^{29,30}$ Therefore, such atomic diffusion is unlikely to be the reason for the observation of 
a significant broadening in the present case, where the substrate stage temperature is only $250^{\circ} \mathrm{C}$. A more likely explanation is the intermixing of $\mathrm{Al}$ and $\mathrm{Zn}$ atoms that can occur easily via surface reactions during ALD growth. ${ }^{31}$ For example, an etching effect has been observed when TMA reacts with a $\mathrm{ZnO}$ surface, $14,32,33$ i.e., TMA can remove surface $\mathrm{Zn}$ atoms, and consequently, $\mathrm{Al}$ atoms can occupy the newly vacant surface sites. This etching effect might introduce downward spreading of $\mathrm{Al}$ atoms, accounting for the asymmetry of the profile mentioned above.

Reconsidering the typical representation of dopant profiles obtained by ALD supercycles, as shown in Figure 1b, it is clear that for $\mathrm{ZnO}: \mathrm{Al}$ films the $\delta$-function distribution is indeed strongly idealized. The $\mathrm{Al}$ distribution is significantly broadened, and hence, for depositions with low cycle ratios, which result in small spacing between layers of $\mathrm{AlO}$ and high doping levels, there will be overlaps of $\mathrm{Al}$ profiles. The latter results in a nonzero local $\mathrm{Al}$ density throughout the entire stack, as also observed in Figure $2 \mathrm{~d}$. The exact shape of the $\mathrm{Al}$ density profile will affect both the conductivity $^{12}$ as well as the doping efficiency, as will be addressed in the Discussion.

Al Distribution at Grain Boundaries. So far, the discussion has focused on the distribution of $\mathrm{Al}$ within the $\mathrm{ZnO}: \mathrm{Al}$ grains. Yet the $\mathrm{ZnO}: \mathrm{Al}$ grain size is by no means infinite, and effects introduced by grain boundaries need to be taken into account. Grain boundaries can have a pronounced influence on the electrical transport properties, e.g., by grain boundary scattering. In order to decrease the resistivity of $\mathrm{ZnO}: \mathrm{Al}$ films, the improvement of the carrier mobility is at least as important as the enhancement of the carrier density. As a matter of fact, it is even preferred to reduce the resistivity by increasing the mobility rather than by increasing the carrier density in cases where free carrier absorption has a negative impact on the functionality of the $\mathrm{ZnO}: \mathrm{Al}$, such as in solar cells. ${ }^{34}$ The carrier mobility of ITO ranges typically from 20 to $40 \mathrm{~cm}^{2} \mathrm{~V}^{-1} \mathrm{~s}^{-1}, 35$ which is significantly higher than that of $\mathrm{ZnO}: \mathrm{Al}\left(\sim 10 \mathrm{~cm}^{2} \mathrm{~V}^{-1} \mathrm{~s}^{-1}\right){ }^{5,12}$ A significant limiting factor causing this difference in carrier mobility is grain boundary scattering. ${ }^{36}$ This scattering has a minor effect for ( $\mathrm{Sn}$ doped) indium oxide due to a low trap density at the grain boundaries $\left(\sim 1.5 \times 10^{12} \mathrm{~cm}^{-2}\right)$ but plays an important role for $\mathrm{ZnO}: \mathrm{Al}$ due to a high trap density $\left(\sim 3 \times 10^{13} \mathrm{~cm}^{-2}\right)$. $^{2}$ Previous work $^{12}$ indicates that the Hall mobility of $\mathrm{ZnO}$ :Al prepared by ALD is typically $80 \%$ of the intragrain mobility. The remaining $20 \%$ difference is ascribed to grain boundary scattering. Therefore, it is also relevant to investigate the $\mathrm{Al}$ distribution at grain boundaries.

In order to study the $\mathrm{Al}$ distribution at grain boundaries, first the morphology of the entire $\mathrm{ZnO} / \mathrm{ZnO}$ :Al stack was imaged by bright-field TEM, as shown in Figure 3a. Grains with a columnargrowth shape throughout the entire stack were observed. On the basis of this image, the width of the grains is estimated to be $\sim 40$ $\mathrm{nm}$. The 3D morphology of the three Al-dopant layers in the AZO-1 film is presented via the APT-derived iso-concentration surfaces of $\mathrm{AF}_{\text {local }}=1.7 \%$ and $\mathrm{AF}_{\text {local }}=3.0 \%$ as shown in Figure $3 \mathrm{~b}$ and $c$, respectively. For clarity, these three Al-dopant layers are indicated by different colors. The $1.7 \%$ iso-concentration surface provides a $3 \mathrm{D}$ representation of the faceted $\mathrm{Al}$-dopant layers shown in the TEM and APT images (Figure $2 \mathrm{~b}$ and $\mathrm{c}$ ). The $3.0 \%$ iso-concentration surface highlights some regions inside the $\mathrm{Al}$ dopant layer that are found to have a further enhanced $\mathrm{Al}$ concentration. The 3.0\% iso-concentration surface has a gridshaped pattern. Especially in the topmost Al-dopant layer, the grid-shaped pattern is more obvious (see also Figure S2) and has a pitch of around $20-30 \mathrm{~nm}$. As a side note, it is important to underline here that these $\mathrm{Al}$ distributions are not caused by the APT analysis itself: the consistency in results between measurements with different laser pulse energies suggests that preferential migration and retention of surface atoms by the APT measurements is not responsible for the $\mathrm{Al}$ enrichment observed in the grain boundaries. ${ }^{37}$

The correlation between the microstructure of $\mathrm{ZnO}$ grains imaged by TEM and the lateral $\mathrm{Al}$ distribution measured by APT is schematically represented in Figure 3d. The transparent parts of the colored planes in Figure $3 \mathrm{~d}$ indicate $\mathrm{Al}$-dopant layers in $\mathrm{ZnO}$ grains with $1.7 \%<\mathrm{AF}_{\text {local }}<3.0 \%$, while the grid-shaped patterns indicate $\mathrm{Al}$-dopant layers at grain boundaries with $\mathrm{AF}_{\text {local }}$ $>3.0 \%$. This can be concluded from the fact that grid-shaped pattern within the planes follows the shape and locations of grain boundaries in the Al-dopant layers, whereas the pitch of the pattern $(\sim 30 \mathrm{~nm})$ corresponds with the grain size in the TEM image ( $30-40 \mathrm{~nm})$. The columnar shape of the $\mathrm{ZnO}$ :Al grains is also consistent with the elongated grains of the entire film stack as shown in Figure 3a.

The formation of the $\mathrm{Al}$ enrichment at grain boundaries can hint at grain boundaries acting as trapping centers of $\mathrm{Al}^{38}$ although also other effects such as preferred etching of TMA on the $\mathrm{ZnO}$ surface at grain boundaries can play a role as well. Such effects can lead to an enrichment of $\mathrm{Al}$ at the intersection between the (predominantly vertical) grain boundaries and at the (mostly horizontal) planes where $\mathrm{Al}$ atoms are incorporated in the $\mathrm{ZnO}$ by the $\mathrm{Al}_{2} \mathrm{O}_{3}$ ALD cycles. On the other hand, no enrichment of $\mathrm{Al}$ is observed in those areas of the grain boundaries in between the $\mathrm{Al}$-dopant layers, suggesting no significant segregation out of the Al-dopant layers.

\section{DISCUSSION}

The APT results in the previous section provide a unique insight into the distribution of the $\mathrm{Al}$ atoms on the $\mathrm{ZnO}$ film matrix. Clearly, the $\mathrm{Al}$ atoms are not distributed according a perfect $\delta$ doping profile, while the $\mathrm{Al}$ atoms are concentrated at distinct film depths. There is a broadened distribution that can even result in overlapping tails when the spacing between the $\mathrm{Al}$ dopant layers is small, which happens at low values of the cycle ratio, $m$. Moreover, it has been observed that there is an enrichment of $\mathrm{Al}$ atoms at grain boundaries. In the view of the results obtained, the issue with limited doping efficiency will be discussed in this section. In particular, two factors influencing the doping efficiency will be addressed: the solubility limit and the disorder-induced carrier localization.

The solid solubility of $\mathrm{Al}$ in the $\mathrm{ZnO}$ matrix is relatively low because $\mathrm{Zn}$ and $\mathrm{Al}$ have different oxidation states, ionic radii, and coordination preferences. ${ }^{39}$ The values of the solubility limit reported in the literature vary. For example, a value of $\mathrm{AF}_{\text {global }}=$ $0.3 \%$ is reported for $\mathrm{ZnO}: \mathrm{Al}$ powders synthesized via the Pechini route and is based on the observation that an additional phase $\mathrm{ZnAl}_{2} \mathrm{O}_{4}$ was detected by X-ray diffraction (XRD) after annealing at very high temperatures $\left(>1000{ }^{\circ} \mathrm{C}\right) .{ }^{39}$ For $\mathrm{ZnO}$ :Al thin films prepared by the sol-gel method ${ }^{40}$ or by the spray pyrolysis technique, ${ }^{41}$ a degradation of the crystallinity of the $\mathrm{ZnO}$ :Al films was observed when $\mathrm{AF}_{\text {global }}>2 \%$. In these literature reports, $\mathrm{AF}_{\text {local }}$ was not measured, but it is fair to assume a homogeneous $\mathrm{Al}$ distribution for the deposition methods employed (although this might not be fully trivial as shown by a recent study on Bdoped $\mathrm{ZnO}$ prepared by low-pressure CVD).$^{42}$ In the case of the $\mathrm{ZnO}: \mathrm{Al}$ thin films grown by ALD, a decrease of crystallinity was observed when $\mathrm{AF}_{\text {global }}>3 \%$. ${ }^{43}$ This value is also in line with the current results in which the grains become heavily disrupted 
when going from AZO-1 to AZO-3 (see Figure 3). Even for $\mathrm{AZO}-1$ with $\mathrm{AF}_{\text {global }}=1.9 \%$, the $\mathrm{Al}$-dopant layers have disrupted the $\mathrm{ZnO}$ grains (see also TEM images in ref 12). The value of $\mathrm{AF}_{\text {global }}=1.9 \%$ for $\mathrm{AZO}-1$ corresponds with $\mathrm{AF}_{\text {local }}$ values up to $\sim 4 \%$ as shown in Figure 2.

The corresponding $\mathrm{Al}-\mathrm{Al}$ interatomic distance $\left(d_{\text {sol }}\right)$ at the solubility limit can be approximated by

$$
d_{\mathrm{sol}} \approx \sqrt[3]{n_{\mathrm{Al}, \mathrm{sol}}}
$$

after calculating $n_{\mathrm{Al} \text {,sol }}$ from $\mathrm{AF}_{\text {local }}$ using the atomic density of $\mathrm{Zn}$ in undoped $\mathrm{ZnO}$. On the basis of the solubility limit values mentioned above $\left(0.3 \% \leq \mathrm{AF}_{\text {local }} \leq 4 \%\right)$, the corresponding value of $d_{\text {sol }}$ is between 0.9 and $2.2 \mathrm{~nm}$. When the local Al density is below the solubility limit $\left(n_{\mathrm{Al}}<n_{\mathrm{Al} . \text { sol }}\right.$ and $\left.d_{\mathrm{Al}-\mathrm{Al}}>d_{\mathrm{sol}}\right)$, the $\mathrm{Al}$ atoms can be substitutionally incorporated in the $\mathrm{Zn}$ positions in the $\mathrm{ZnO}$ matrix and effectively act as electron donors. When the local $\mathrm{Al}$ density is above the solubility limit $\left(n_{\mathrm{Al}}>n_{\mathrm{Al} \text {.sol }}\right.$ and $d_{\mathrm{Al}-\mathrm{Al}}$ $<d_{\text {sol }}$ ), a fraction of the $\mathrm{Al}$ atoms may form $\mathrm{AlO}_{x}$ clusters or $\mathrm{ZnAl}_{2} \mathrm{O}_{4}$ compounds or segregate to the grain boundaries. These $\mathrm{Al}$ atoms are unlikely to act as electron donors. Therefore, the doping efficiency is lower when the local $\mathrm{Al}$ density becomes too high.

The reduced doping efficiency at high doping levels can also result from disorder-induced carrier localization. In the literature, it has been reported that intrinsic defects, such as oxygen vacancies $\left(\mathrm{V}_{\mathrm{O}}{ }^{2+}\right),{ }^{44,45}$ and extrinsic defects, such as substitutional dopant atoms at zinc sites (e.g., $\left.\mathrm{Ga}_{\mathrm{Zn}}{ }^{+}\right),{ }^{46}$ can cause disorder in the $\mathrm{ZnO}$ lattice. During electrical transport, electrons can be backscattered by such disorder, leading to the self-interference of coherent electron wave functions. ${ }^{44}$ As a result, the scattered electrons are weakly localized, which limits the contribution of the electrons to the conductivity. ${ }^{46}$ The inelastic diffusion length $\left(L_{\text {in }}\right)$ can be expressed by ${ }^{46}$

$$
L_{\text {in }}=\sqrt{D \tau_{\text {in }}}=\sqrt{\hbar D / k_{\mathrm{B}} T}
$$

where $D$ is the electron diffusion coefficient, $\tau_{\text {in }}$ is the inelastic relaxation time, and $\hbar, k_{\mathrm{B}}$, and $T$ are the reduced Planck constant, Boltzmann constant, and absolute temperature, respectively. With increasing doping levels, the lattice disorder increases. When the interatomic distance between dopant impurities is smaller than $L_{\text {in }}$, electrons start to interfere constructively. ${ }^{46}$ Applying this theory to the $\mathrm{ZnO}: \mathrm{Al}$ case, the value of $\mathrm{D}$ is $\sim 0.213$ $\mathrm{cm}^{2} / \mathrm{s}$ in the $\mathrm{ZnO}$ matrix, ${ }^{46}$ resulting in $L_{\text {in }}=\sim 0.74 \mathrm{~nm}$ at room temperature $(T=298 \mathrm{~K})$. It is reasonable to propose that when the interatomic distance of $\mathrm{Al}$ is smaller than $L_{\mathrm{in}}$, i.e., $d_{\mathrm{Al}-\mathrm{Al}}<$ $\sim 0.74 \mathrm{~nm}$, weak localization of electrons will become significant. These weakly localized electrons may not (fully) contribute to the carrier density measured by the Hall measurements and hence negatively affect the calculated doping efficiency.

In summary, the $\mathrm{Al}-\mathrm{Al}$ interatomic distance at the solubility limit $\left(d_{\text {sol }}\right)$ and the inelastic diffusion length are both on the order of $\sim 1 \mathrm{~nm}$. Therefore, to obtain a high doping efficiency, an $\mathrm{Al}-\mathrm{Al}$ interatomic distance $d_{\mathrm{Al}-\mathrm{Al}}>\sim 1 \mathrm{~nm}$ is desired, which corresponds to a local Al density $n_{\mathrm{Al}}<\sim 1 \mathrm{~nm}^{-3}$, i.e., $\mathrm{AF}_{\text {local }}<$ $\sim 2.5 \%$. The measured $\mathrm{Al}$ concentrations in the three profiles displayed in Figure 2d appear to exceed this doping level, either over the full thickness of the stack (AZO-3) or locally (AZO-1 and AZO-2). This indicates that at the positions where ALD $\mathrm{Al}_{2} \mathrm{O}_{3}$ cycles are inserted during film growth, the density of incorporated $\mathrm{Al}$ atoms is too high to obtain an optimal conductivity and doping efficiency. On the other hand, the aforementioned broadening of the $\mathrm{Al}$ profiles has a beneficial effect on the doping efficiency in the AZO-1 and AZO-2 stacks, as a smaller fraction of the $\mathrm{Al}$ contributes to cluster formation than in the case of a $\delta$-doped layer. In order to achieve a higher doping efficiency, the amount of $\mathrm{Al}$ atoms incorporated during one ALD $\mathrm{Al}_{2} \mathrm{O}_{3}$ cycle should be reduced. This hypothesis is supported by other experiments, described in refs 14 and 15 where it was found that deposition processes that reduce the number of incorporated $\mathrm{Al}$ atoms give rise to a significant enhancement of doping efficiency.

\section{CONCLUSIONS}

In this work, the $\mathrm{Al}$ distribution in $\mathrm{ALD}$-prepared $\mathrm{ZnO}$ : $\mathrm{Al}$ films and its effect on doping efficiency have been investigated. The 3D spatial distribution of $\mathrm{Al}$ in the $\mathrm{ZnO}: \mathrm{Al}$ thin films has been examined on an atomic scale using the combination of TEM and $\mathrm{APT}$. It has been found that the $\mathrm{ZnO}: \mathrm{Al}$ films are characterized by layers with a high local $\mathrm{Al}$ concentration. These layers are not $\delta$-layers but rather exhibit a vertical concentration profile, which causes overlapping of the $\mathrm{Al}$ distributions of adjacent $\mathrm{Al}$-dopant layers. Because of the solubility limit of $\mathrm{Al}$ in $\mathrm{ZnO}$ and the disorder-induced carrier localization, a high local $\mathrm{Al}$ density will result in a low doping efficiency. In addition, an enrichment of $\mathrm{Al}$ at grain boundaries is observed at intervals corresponding to layers where $\mathrm{Al}$ atoms are incorporated. Such a better understanding of the correlation between growth parameters, atomic distribution, and electrical performance can prove to be helpful for future optimizations of the film resistivity of TCOs prepared by ALD.

\section{ASSOCIATED CONTENT}

\section{Supporting Information}

The Supporting Information is available free of charge on the ACS Publications website at DOI: 10.1021/acs.chemmater.7b03501.

Simulated one-dimensional $\mathrm{Al}$ fractions in the $\mathrm{ZnO}: \mathrm{Al}$ films and two-dimensional color maps of the isoconcentration surfaces of $\mathrm{Al}$ in the $\mathrm{ZnO}: \mathrm{Al}$ film $\mathrm{AZO}-1$ (PDF)

\section{AUTHOR INFORMATION}

\section{Corresponding Author}

*E-mail: w.m.m.kessels@tue.nl.

ORCID $\odot$

Bart Macco: 0000-0003-1197-441X

Wilhelmus M. M. Kessels: 0000-0002-7630-8226

\section{Notes}

The authors declare no competing financial interest.

\section{ACKNOWLEDGMENTS}

The authors thank Holst Centre/IMEC-NL, The Netherlands, for financially supporting this project. This research has also received funding from the European Union's Horizon 2020 research and innovation programme under grant agreement No. 641864 (INREP). The funding of the atomic resolution TEM facility by the Dutch province of Noord-Brabant as well as the fruitful discussions with Dr. A. Illiberi (TNO) and Prof. Dr. P. Koenraad (Eindhoven University of Technology) are gratefully acknowledged. The research of W.M.M.K. has been made possible by the Dutch Technology Foundation STW and The Netherlands Organization for Scientific Research (NWO, VICI program). 


\section{REFERENCES}

(1) Hosono, H.; Ohta, H.; Orita, M.; Ueda, K.; Hirano, M. Frontier of Transparent Conductive Oxide Thin Films. Vacuum 2002, 66 (3-4), 419-524.

(2) Ellmer, K.; Mientus, R. Carrier Transport in Polycrystalline ITO and $\mathrm{ZnO}$ : Al II: The Influence of Grain Barriers and Boundaries. Thin Solid Films 2008, 516 (17), 5829-5835.

(3) Nomura, K.; Ohta, H.; Takagi, A.; Kamiya, T.; Hirano, M.; Hosono, H. Room-Temperature Fabrication of Transparent Flexible Thin-Film Transistors Using Amorphous Oxide Semiconductors. Nature 2004, 432 (7016), 488-492.

(4) Fortunato, E.; Ginley, D.; Hosono, H.; Paine, D. C. Transparent Conducting Oxides for Photovoltaics. MRS Bull. 2007, 32 (March), 242-247.

(5) Minami, T. Transparent Conducting Oxide Semiconductors for Transparent Electrodes. Semicond. Sci. Technol. 2005, 20 (4), S35-S44.

(6) George, S. M. Atomic Layer Deposition: An Overview. Chem. Rev. 2010, 110 (1), 111-131.

(7) Profijt, H. B.; Potts, S. E.; van de Sanden, M. C. M.; Kessels, W. M. M. Plasma-Assisted Atomic Layer Deposition: Basics, Opportunities, and Challenges. J. Vac. Sci. Technol., A 2011, 29 (5), 50801.

(8) Lee, D.-J.; Kim, H.-M.; Kwon, J.-Y.; Choi, H.; Kim, S.-H.; Kim, K.B. Structural and Electrical Properties of Atomic Layer Deposited AlDoped ZnO Films. Adv. Funct. Mater. 2011, 21 (3), 448-455.

(9) Dasgupta, N. P.; Neubert, S.; Lee, W.; Trejo, O.; Lee, J.-R.; Prinz, F. B. Atomic Layer Deposition of Al-Doped ZnO Films: Effect of Grain Orientation on Conductivity. Chem. Mater. 2010, 22 (16), 4769-4775.

(10) Tynell, T.; Karppinen, M. Atomic Layer Deposition of ZnO: A Review. Semicond. Sci. Technol. 2014, 29, 43001.

(11) Macco, B.; Deligiannis, D.; Smit, S.; van Swaaij, R. A. C. M. M.; Zeman, M.; Kessels, W. M. M. Influence of Transparent Conductive Oxides on Passivation of a-Si:H/c-Si Heterojunctions as Studied by Atomic Layer Deposited Al-Doped ZnO. Semicond. Sci. Technol. 2014, 29 (12), 122001.

(12) Wu, Y.; Hermkens, P. M.; van de Loo, B. W. H.; Knoops, H. C. M.; Potts, S. E.; Verheijen, M. A.; Roozeboom, F.; Kessels, W. M. M. Electrical Transport and Al Doping Efficiency in Nanoscale ZnO Films Prepared by Atomic Layer Deposition. J. Appl. Phys. 2013, 114 (2), 24308.

(13) Yanguas-Gil, A.; Peterson, K. E.; Elam, J. W. Controlled Dopant Distribution and Higher Doping Efficiencies by Surface-Functionalized Atomic Layer Deposition. Chem. Mater. 2011, 23, 4295-4297.

(14) Wu, Y.; Potts, S. E.; Hermkens, P. M.; Knoops, H. C. M.; Roozeboom, F.; Kessels, W. M. M. Enhanced Doping Efficiency of AlDoped $\mathrm{ZnO}$ by Atomic Layer Deposition Using Dimethylaluminum Isopropoxide as an Alternative Aluminum Precursor. Chem. Mater. 2013, 25 (22), 4619-4622.

(15) Garcia-Alonso, D.; Potts, S. E.; van Helvoirt, C. A. A.; Verheijen, M. a.; Kessels, W. M. M. Atomic Layer Deposition of B-Doped ZnO Using Triisopropyl Borate as the Boron Precursor and Comparison with Al-Doped ZnO. J. Mater. Chem. C 2015, 3 (13), 3095-3107.

(16) Jaramillo, R.; Youssef, A.; Akey, A.; Schoofs, F.; Ramanathan, S.; Buonassisi, T. Using Atom-Probe Tomography to Understand ZnO:Al/ SiO2/Si Schottky Diodes. Phys. Rev. Appl. 2016, 6, 34016.

(17) Wu, Y.; Macco, B.; Vanhemel, D.; Kölling, S.; Verheijen, M. A.; Koenraad, P. M.; Kessels, W. M. M.; Roozeboom, F. Atomic Layer Deposition of In2O3:H from InCp and H2O/O2: Microstructure and Isotope Labeling Studies. ACS Appl. Mater. Interfaces 2017, 9, 592-601. (18) Scappucci, G.; Klesse, W. M.; Hamilton, A. R.; Capellini, G.; Jaeger, D. L.; Bischof, M. R.; Reidy, R. F.; Gorman, B. P.; Simmons, M. Y. Stacking of 2D Electron Gases in Ge Probed at the Atomic Level and Its Correlation to Low-Temperature Magnetotransport. Nano Lett. 2012, 12 (9), 4953-4959.

(19) Shimizu, Y.; Takamizawa, H.; Inoue, K.; Yano, F.; Nagai, Y.; Lamagna, L.; Mazzeo, G.; Perego, M.; Prati, E. Behavior of Phosphorus and Contaminants from Molecular Doping Combined with a Conventional Spike Annealing Method. Nanoscale 2014, 6 (2), 706710 .
(20) Thompson, K.; Larson, D. J.; Ulfig, R. Pre-Sharpened and FlatTop Microtip Coupons: A Quantitative Comparison for Atom-Probe Analysis Studies. Microsc. Microanal. 2005, 11 (Suppl 2), 2004-2005.

(21) Larson, D. J.; Foord, D. T.; Petford-Long, A. K.; Liew, H.; Blamire, M. G.; Cerezo, A.; Smith, G. D. W. Field-Ion Specimen Preparation Using Focused Ion-Beam Milling. Ultramicroscopy 1999, 79 (1-4), 287-293.

(22) Miller, M. K.; Russell, K. F.; Thompson, K.; Alvis, R.; Larson, D. J. Review of Atom Probe FIB-Based Specimen Preparation Methods. Microsc. Microanal. 2007, 13 (6), 428-436.

(23) Kelly, T. F.; Larson, D. J. Atom Probe Tomography 2012. Annu. Rev. Mater. Res. 2012, 42 (1), 1-31.

(24) Vurpillot, F.; Cerezo, A.; Blavette, D.; Larson, D. J. Modeling Image Distortions in 3DAP. Microsc. Microanal. 2004, 10 (3), 384-390.

(25) Larson, D. J.; Geiser, B. P.; Prosa, T. J.; Kelly, T. F. On the Use of Simulated Field-Evaporated Specimen Apex Shapes in Atom Probe Tomography Data Reconstruction. Microsc. Microanal. 2012, 18 (5), 953-963.

(26) Koelling, S.; Gilbert, M.; Goossens, J.; Hikavyy, A.; Richard, O.; Vandervorst, W. High Depth Resolution Analysis of Si/SiGe Multilayers with the Atom Probe. Appl. Phys. Lett. 2009, 95 (14), 144106.

(27) Vurpillot, F.; Da Costa, G.; Menand, A.; Blavette, D. Structural Analyses in Three-Dimensional Atom Probe: A Fourier Transform Approach. J. Microsc. 2001, 203 (3), 295-302.

(28) Shimizu, Y.; Kawamura, Y.; Uematsu, M.; Tomita, M.; Kinno, T.; Okada, N.; Kato, M.; Uchida, H.; Takahashi, M.; Ito, H.; Ishikawa, H.; Ohji, Y.; Takamizawa, H.; Nagai, Y.; Itoh, K. M. Depth and Lateral Resolution of Laser-Assisted Atom Probe Microscopy of Silicon Revealed by Isotopic Heterostructures. J. Appl. Phys. 2011, 109 (3), 36102.

(29) Nakagawa, T.; Sakaguchi, I.; Matsumoto, K.; Uematsu, M.; Haneda, H.; Ohashi, N. Observation of Diffusion Behavior in AlImplanted ZnO Single Crystal. Key Eng. Mater. 2009, 421-422, 197200.

(30) Johansen, K. M.; Vines, L.; Bjørheim, T. S.; Schifano, R.; Svensson, B. G. Aluminum Migration and Intrinsic Defect Interaction in Single-Crystal Zinc Oxide. Phys. Rev. Appl. 2015, 3 (2), 24003.

(31) Knez, M. Diffusion Phenomena in Atomic Layer Deposition. Semicond. Sci. Technol. 2012, 27 (7), 74001.

(32) Na, J.-S.; Scarel, G.; Parsons, G. N. In Situ Analysis of Dopant Incorporation, Activation, and Film Growth during Thin Film $\mathrm{ZnO}$ and ZnO: Al Atomic Layer Deposition. J. Phys. Chem. C 2010, 114, 383388.

(33) Elam, J.; George, S. Growth of $\mathrm{ZnO} / \mathrm{Al} 2 \mathrm{O} 3$ Alloy Films Using Atomic Layer Deposition Techniques. Chem. Mater. 2003, 15, 10201028.

(34) Berginski, M.; Hüpkes, J.; Schulte, M.; Schöpe, G.; Stiebig, H.; Rech, B.; Wuttig, M. The Effect of Front ZnO: Al Surface Texture and Optical Transparency on Efficient Light Trapping in Silicon Thin-Film Solar Cells. J. Appl. Phys. 2007, 101 (7), 74903.

(35) De Wolf, S.; Descoeudres, A.; Holman, Z. C.; Ballif, C. HighEfficiency Silicon Heterojunction Solar Cells: A Review. Green 2012, 2 (1), 7-24.

(36) Ellmer, K.; Mientus, R. Carrier Transport in Polycrystalline Transparent Conductive Oxides: A Comparative Study of Zinc Oxide and Indium Oxide. Thin Solid Films 2008, 516 (14), 4620-4627.

(37) Tu, Y.; Takamizawa, H.; Han, B.; Shimizu, Y.; Inoue, K.; Toyama, T.; Yano, F.; Nishida, A.; Nagai, Y. Influence of Laser Power on Atom Probe Tomographic Analysis of Boron Distribution in Silicon. Ultramicroscopy 2017, 173, 58-63.

(38) Suzuoka, T. Lattice and Grain Boundary Diffusion in Polycrystals. Trans. Jpn. Inst. Met. 1961, 2, 25-33.

(39) Serier, H.; Gaudon, M.; Ménétrier, M. Al-Doped ZnO Powdered Materials: Al Solubility Limit and IR Absorption Properties. Solid State Sci. 2009, 11 (7), 1192-1197.

(40) Zi-Qiang, X.; Hong, D.; Yan, L.; Hang, C. Al-Doping Effects on Structure, Electrical and Optical Properties of c-Axis-Orientated $\mathrm{ZnO}$ : Al Thin Films. Mater. Sci. Semicond. Process. 2006, 9 (1-3), 132-135. 
(41) El Manouni, A.; Manjón, F. J.; Perales, M.; Mollar, M.; Marí, B.; Lopez, M. C.; Ramos Barrado, J. R. Effect of Thermal Annealing on ZnO: Al Thin Films Grown by Spray Pyrolysis. Superlattices Microstruct. 2007, 42 (1-6), 134-139.

(42) Lorenzo, F.; Aebersold, A. B.; Morales-Masis, M.; Ledinský, M.; Escrig, S.; Vetushka, A.; Alexander, D. T. L.; Hessler-Wyser, A.; Fejfar, A.; Hébert, C.; Nicolay, S.; Ballif, C. Direct Imaging of Dopant Distribution in Polycrystalline $\mathrm{ZnO}$ Films. ACS Appl. Mater. Interfaces 2017, 9, 7241.

(43) Banerjee, P.; Lee, W.-J.; Bae, K.-R.; Lee, S. B.; Rubloff, G. W. Structural, Electrical, and Optical Properties of Atomic Layer Deposition Al-Doped ZnO Films. J. Appl. Phys. 2010, 108 (4), 43504.

(44) Saha, D.; Das, A. K.; Ajimsha, R. S.; Misra, P.; Kukreja, L. M. Disorder-Driven Carrier Transport in Atomic Layer Deposited ZnO Thin Films. arXiv Prepr. 2013, arXiv: 1301.1172

(45) Tiwari, A.; Jin, C.; Narayan, J.; Park, M. Electrical Transport in $\mathrm{ZnO}$ 1- $\delta$ Films: Transition from Band-Gap Insulator to Anderson Localized Insulator. J. Appl. Phys. 2004, 96 (7), 3827-3830.

(46) Bhosle, V.; Tiwari, A.; Narayan, J. Electrical Properties of Transparent and Conducting Ga Doped ZnO. J. Appl. Phys. 2006, 100 (3), 33713. 